\title{
Percepções sobre 0 aborto legal entre partidários da extrema direita: 0 caso da criança capixaba de 10 anos
}

\author{
Paulo Henrique Dantas ${ }^{1}$ \\ Priscilla Dibai $^{2}$
}

\section{Resumo}

Analisamos valores e crenças exteriorizados por partidários da extrema direita brasileira, autodeclarados apoiadores do presidente Jair Bolsonaro, em relação ao aborto legal de uma criança capixaba de 10 anos, estuprada por familiar, ocorrido em agosto de 2020 . A coleta de dados ocorreu entre 13 e 21/08/20, em uma comunidade virtual pró-presidente, resultando em um corpus de 295 mensagens de texto e 42 imagens. A pesquisa buscou responder como os partidários valoraram o caso, quais sentidos agregaram ao aborto, quais atores/instituições foram mencionados ou cobrados e quais soluções foram propostas ou referendadas. Como resultado, identificamos posições predominantemente contrárias ao aborto legal - não entendido como direito, mas como crime -, bem como construções estereotipadas das mulheres, famílias, profissionais de saúde e políticas relacionadas à temática abortiva. 0 desejo por leis mais rígidas, a fé cristã e o sentimento antiesquerda apareceram fortemente vinculados ao tema, com relevante influência na modalização da opinião antiaborto.

\section{Palavras-chave}

Aborto legal. Extrema direita. Bolsonarismo. Redes sociais.

\section{Abstract}

We've analyzed values and beliefs expressed by supporters of the Brazilian far right, self-declared supporters of President Jair Bolsonaro, in relation to the legal abortion of a 10-year-old child from Espírito Santo, raped by a family member, which occurred in August 2020. Data collection took place between the 13th and 21st of August 2020, in a online pro-president community, resulting in a corpus of 295 text messages and 42 images. The research sought to answer how supporters valorized the case, which meanings they added to abortion, which actors/institutions were mentioned or demanded and which solutions were proposed or endorsed. As a result, we've identified positions predominantly against legal abortion - not understood as a right, but as a

\footnotetext{
1 Doutorando em Sociologia pela Universidade Estadual de Campinas (UNICAMP). E-mail: paulohenrique.ba@gmail.com.

2 Doutoranda no Programa de Pós-graduação em Comunicação e Cultura Contemporâneas da Universidade Federal da Bahia (POSCOM-UFBA). E-mail: pdibai@gmail.com.
} 
crime - as well as stereotyped constructions of women, families, health professionals and policies related to abortion issues. The desire for stricter laws, Christian faith and anti-left sentiment appeared strongly linked to the theme, with a relevant influence in the modalization of antiabortion opinion.

\section{Keywords}

Legal abortion. Far-right. Bolsonarism. Social media.

\section{Introdução}

Sendo o aborto legal um tema controverso na sociedade brasileira e considerando que uma direita mais radical governa o país, analisamos como partidários do presidente da República, Jair Bolsonaro, os quais consideramos pertencentes ao espectro político da extrema direita, repercutiram o caso da menina capixaba de 10 anos, grávida por estupro, que teve o direito de abortar autorizado pela Justiça. $\mathrm{O}$ objetivo do artigo foi identificar os sentidos construídos, argumentos mobilizados e soluções apontadas em torno do tema.

O episódio da menina grávida ganhou repercussão nacional e reacendeu, ainda que momentaneamente, a discussão sobre o aborto no Brasil. Com 10 anos, ela descobriu a gravidez em uma unidade pública de saúde de São Mateus (ES), com 20 semanas de gestação (quase cinco meses). Após o diagnóstico, a garota revelou que era estuprada desde os seis anos pelo tio (marido da tia consanguínea). Uma semana depois (14/08/20), a Justiça do Espírito Santo autorizou a interrupção da gestação.

No Brasil, a prática abortiva é tipificada legal quando a gravidez resulta de abuso sexual ou coloca em risco a saúde da mulher (artigo 128 da Lei 2.848, de dezembro de 1940). Em 2012, por decisão do Supremo Tribunal Federal (STF), acresceu-se a essa lista a possibilidade de interromper a gravidez em situações em que o feto é anencéfalo, ou seja, não possui cérebro.

A criança capixaba realizou o aborto legal em Recife (PE), no dia 17/08, após o hospital de referência do Espírito Santo alegar incapacidade técnica para o procedimento. Grupos religiosos ou antiaborto protestaram contra a suspensão da gestação e até tentaram invadir a maternidade pernambucana, depois que a apoiadora de Bolsonaro, Sara Giromini (Sara Winter) ${ }^{3}$, publicou na internet o

\footnotetext{
${ }^{3}$ Sara Giromini se declara ex-feminista. Apoiadora de Jair Bolsonaro, foi líder do grupo paramilitar "300 do Brasil", bem como servidora do Ministério da Mulher, Família e Direitos Humanos.
} 
nome completo da vítima e o hospital de atendimento ${ }^{4}$. A conduta de Sara violou tanto o Estatuto da Criança e do Adolescente (ECA) quanto é passível de crime no Código Penal Brasileiro. Associações feministas também estiveram no local para pressionar pelo cumprimento da lei e pelo direito da menina de abortar.

A ministra da Mulher, Família e Direitos Humanos, Damares Alves, evangélica, foi denunciada pela mídia por usar a estrutura do ministério para impedir a realização do procedimento (VILA-NOVA, 2020). Personalidades e comunicadores que apoiam o presidente também se manifestaram contrários. O pastor evangélico Silas Malafaia chamou o juiz que autorizou o aborto de "desgraçado assassino" e que ele merecia "estar na cadeia". O blogueiro Bernardo Kuster", que aderiu à retórica "pelas 2 vidas", iniciada por Giromini, afirmou no Twitter que a esquerda fazia de tudo para "matar a criancinha no ventre materno" e acusou o médico do hospital pernambucano de "forçar o aborto".

No mesmo dia em que a menina realizou o procedimento, o filho do presidente e deputado federal Eduardo Bolsonaro apresentou projeto de lei para castração química de estupradores, tal qual fez seu pai, em 2013, em proposta arquivada, à época. Dias antes (10/8/20, no Twitter), ele compartilhou e comentou a notícia falsa (do site bolsonarista Brasil sem Medo) de que a França autorizara aborto até o nono mês de gestação, escrevendo: “Deus tenha piedade do povo francês e dos bebês que, inocentes, serão assassinados sem culpa...".

Sobre o caso da menina grávida, jornais internacionais destacaram "extremismo" e "fundamentalismo religioso" incensados pelo governo Bolsonaro $^{6}$. O ministro do STF, Luís Roberto Barroso, também alertou sobre o "fanatismo religioso" em torno da ocorrência. Outros ministros da Corte defenderam, na imprensa, a legalidade da interrupção, bem como fez a OAB (Ordem dos Advogados do Brasil).

Embora o presidente Jair Bolsonaro não tenha se pronunciado especificamente sobre o caso, declarou este ano, em duas ocasiões diferentes,

Chegou a ser presa, em 2020, no inquérito federal contra atos antidemocráticos.

${ }^{4}$ Em função disso, o Youtube cancelou a conta de Giromini. A Justiça do Espírito Santo também determinou que outras mídias sociais excluíssem suas publicações.

${ }^{5}$ Kuster é alvo do Supremo Tribunal Federal no inquérito das Fake News, bem como por incitar atos contra a democracia.

${ }^{6}$ Ver em: <https://www.dw.com/pt-br/imprensa-europeia-repercute-pol\%C3\%AAmica-sobreaborto-no-brasil/a-54608585>. Acesso em: 15 out. 2020. 
que, enquanto fosse presidente, não haveria aborto ${ }^{7}$. Também propôs, junto com Donald Trump, firmar uma aliança internacional em "defesa da família" e contra políticas abortivas (CHADE, 2020). Dez dias depois de a menina abortar, em 27/08/20, Bolsonaro autorizou a Portaria 2.282, que propunha novas regras para dificultar o aborto em vítimas de estupro ${ }^{8}$. A medida foi rechaçada por médicos, juristas e pelo então presidente da Câmara, Rodrigo Maia, que considerou a medida "ilegal" e "inconstitucional".

Para fins de contextualização, o Ministério da Saúde contabilizou 1.636 abortos legais no Brasil, em 2017. Nos seis anos anteriores, 4.262 adolescentes de 10 a 19 anos mantiveram a gravidez em decorrência de estupros, pois não foram atendidas pelo sistema de saúde. Dessas, 1.875 tinham entre 10 e 14 anos de idade. Em aproximadamente sete de cada dez casos, o estuprador era da família (SOARES; NOVAIS, 2019). Em relação ao aborto não legal, estima-se que três em cada dez mulheres abortam no Brasil, segundo a Organização Mundial de Saúde (OMS). Pelos dados do Ministério da Saúde, a taxa seria de 3,7 interrupções para cada 100 mulheres de 15 a 49 anos. Já pela pesquisa de Diniz, Medeiros e Madeiro (2017), aos 40 anos, quase 1 em cada 5 brasileiras já fez um aborto.

\section{Procedimentos metodológicos}

Os dados analisados foram extraídos de uma comunidade virtual de partidários do presidente da República, hospedada na plataforma Telegram ${ }^{9}$, entre os dias 13 e 22 de agosto de 2020. No momento da coleta, o grupo, que é aberto, possuía 37 mil inscritos. Os conteúdos foram exportados via Telegram Desktop. A exportação é permitida a qualquer integrante e feita de forma

\footnotetext{
${ }^{7}$ Comentário foi feito à imprensa pelo menos duas vezes este ano, em abril e junho de 2020. Ver em:

<https://www.correiobraziliense.com.br/app/noticia/politica/2020/04/23/interna_politica,847 443/enquanto-eu-for-presidente-nao-havera-diz-bolsonaro-sobre-aborto.shtml>. Acesso em: 15 out. 2020. e/ou <https://www1.folha.uol.com.br/equilibrioesaude/2020/06/apos-pressao-debolsonaro-ministerio-da-saude-retira-do-ar-nota-tecnica-que-cita-acesso-a-aborto-legal.shtml> . Acesso em: 15 out. 2020.

8 A modificação obrigava profissionais de saúde a notificarem autoridades policiais antes da realização do aborto, mesmo com risco de morte à mãe. Em setembro, a portaria retornou ao molde anterior.

${ }^{9} \mathrm{O}$ aplicativo, que concorre com o WhatsApp, permite a criação de grupos com até 200.000 membros. $\mathrm{O}$ administrador pode fixar mensagem aos usuários e gerenciar bots para variadas funções.
} 
automática pelo próprio aplicativo, que gera pastas específicas com arquivos em HTML (mensagens de texto) e JPG (imagens).

Ainda que seja crescente o interesse pelo estudo de mídias digitais e plataformas de conversação on-line, diante da necessidade de aprofundamento em torno do debate das relações sociais digitalizadas, os desafios ainda são grandes. O sofisticado sistema de criptografia de ponta a ponta dos aplicativos e a recusa de parte significativa da direita radical brasileira em participar de pesquisas acadêmicas são alguns deles. Sendo assim, a estratégia têm sido ingressar nesses grupos de forma anônima e não participante.

Por questões éticas, a pesquisa não expõe nem menciona, direta ou indiretamente, nomes, arrobas, nicknames ou números telefônicos, apagados assim que os dados são compilados. Da mesma forma, não reproduzimos mensagens de texto, trabalhando-as de forma indireta. É importante pontuar que os administradores da comunidade virtual deletam a conversação quase que diariamente, de modo que tais arquivos não ficam disponíveis nem mesmo aos próprios membros, exceto àqueles que, porventura, tivessem o rigor de exportar a conversação cotidianamente.

Como se trata de um grupo de conversação instantânea on-line em que os participantes conversam sobre quaisquer assuntos, em tempo real, por meio de diferentes recursos, optamos por filtrar o conteúdo e trabalhar apenas com mensagens de texto e imagens que fazem referência direta à temática, de modo que áudios, links, vídeos e stickers foram descartados, enquanto fotos, cards, prints de tela, montagens foram admitidos. Esclarecemos que a interação segue o ritmo dado pelos próprios integrantes, sem qualquer mediação, estímulo ou interferência por parte dos pesquisadores, de modo que o ambiente da pesquisa não é controlado. Assim, a conversa ocorre em um ambiente fragmentado, informal, criativo, multifacetado por temas variados, com presença de apelidos, gírias, erros de grafia e concordância, falas incompletas e uma série de outras marcas arbitrárias que, embora dificultem a sistematização, são dribláveis e não comprometem os resultados.

Para formar o corpus, lemos a conversação no período, bem como utilizamos o recurso da busca por palavras-chave para um melhor monitoramento. Os radicais utilizados foram: abort; estupr; menina; criança; gravid, pedofil e sara ${ }^{10}$, de modo que todas as mensagens que continham pelo menos um dos termos foram pré-selecionadas e posteriormente avaliadas, para identificar se, de fato, tinham conformidade com o caso de interesse. Mensagens não relacionadas

${ }^{10}$ Faz referência a Sara Giromini. 
foram descartadas. Sobre as imagens, visualizamos todo o arquivo e selecionamos as condizentes com a temática. Ao final, fechamos o banco de dados com 295 mensagens de texto e 42 imagens (diferentes, sem repetição).

Para a análise, lemos cuidadosamente o material e, na sequência, codificamos o texto (classificação das passagens em categorias teóricoempíricas), em um Computer assisted data analysis software (CAQDAS11). Essa etapa permite, ao final, sistematizar e comparar achados (BAUER, 2015). Depois, com as fotos, avaliamos o teor/tom, interessados nos sentidos, personagens abordados e inimigos apontados. Trabalhamos o conteúdo a partir de quatro perguntas centrais: 1) Considerando as mensagens que valoraram o aborto, quais argumentos foram atribuídos em sua defesa ou repúdio? 2) Considerando as mensagens que não valoraram o aborto, que sentidos trouxeram ao caso? 3) Personalidades, instituições ou grupos foram atacados a partir do caso? Quais? 4) Quais soluções foram apresentadas para o aborto a partir do caso?

Primeiramente, mapeamos as postagens pró e contra o aborto (classificadas em cinco níveis - de abertamente favorável até abertamente contra, passando por favorável com ressalva, contrário com ressalva e não opina); depois levantamos fontes de ataques, responsabilizações e soluções, formando uma lista de códigos: 1) Ataque à esquerda; 2) Ataque à mídia; 3) Ataque a Sara Winter; 4) Responsabilização da família e/ou conhecidos; 5) Responsabilização do estuprador; 6) Leis mais rígidas; 7) Apelos religiosos. Também criamos uma categoria "Outros" para os discursos fragmentados ou não relevantes, por exemplo, lamentações sem valoração do aborto, perguntas, referência ao contexto internacional, links de matérias etc.

\section{Discussão com a literatura}

Embora a defesa dos valores tradicionais e as disputas em torno do gênero não sejam novos no Brasil (PIERUCCI, 1987; SOLANO, 2018; SOLANO, 2019a; ALMEIDA, 2019a, 2019b; BIROLI; CAMINOTTI, 2020), é razoável admitir que a ascensão de Jair Bolsonaro enquanto liderança da extrema direita deu novo fôlego a essas pautas (MARANHÃO; COELHO; DIAS, 2018), aglutinando ou fortalecendo os setores mais reacionários e ultraconservadores (ALMEIDA, 2019a, 2019b). Como pontua Alonso (2019), a ascensão de Bolsonaro dialogou diretamente com os grupos mais aflitos diante da modificação dos costumes,

${ }^{11} \mathrm{O}$ CAQDAS Atlas.TI versão 7.5.18 foi utilizado no processo de codificação. 
que queriam a todo custo restaurar a hierarquia de gênero, a predominância do casamento heterossexual, a orientação religiosa da conduta e a educação estruturada na autoridade.

Ao longo da carreira política, Bolsonaro foi contrário a uma série de mudanças ocorridas em relação às minorias, sexualidade, gênero e reprodução implementadas pelos governos petistas (DIBAI, 2018; ALMEIDA, 2019b). Desde 2011, com o episódio forjado do "kit gay", vem se apresentando como defensor da família exclusivamente heterossexual e acusando a esquerda de ameaçar os valores tradicionais (MARANHÃO; COELHO; DIAS, 2018; DIBAI, 2018). Como parte desse pânico sociomoral, explora a ideia de que há uma ideologia ("ideologia de gênero") perversa e pervertida que erotiza, viola e desumaniza crianças, que coloca em risco o casamento, a ordem natural e os valores nacionais (BIROLI; CAMINOTTI, 2020), além de simular riscos correlacionados: "abortismo" ${ }^{12}$, adoção por casais gays, conversão automática de meninos em meninas (e vice-versa) pela escola, educação comunista etc.

Pesquisas anteriores notaram a preocupação de adeptos do bolsonarismo com a "desordem" de costumes e ameaças à ordem familiar (SOLANO, 2018; KALIL et al., 2018). Grande parte desse incômodo provinha de questões como direitos dos homossexuais, legalização do aborto e das drogas, além de medo do desregramento sexual (KALIL et al., 2018; SOLANO, 2018). Messenberg (2019) identificou a defesa da família tradicional e o desejo de resgate da fé cristã como "ideias-chave" do conservadorismo moral que reacendeu no Brasil, em meados dos anos 2010. Entre os elementos invocados, ela apontou aversão ao casamento gay, ao aborto, à ideologia de gênero nas escolas, ao comunismo, à expansão do feminismo e à concordância com a "cura gay".

A ideia de família tradicional (reconhecida como um núcleo composto, obrigatoriamente, por homem, mulher e filhos) tem funcionado como o "signo mais englobante do campo moral em questões relativas ao corpo, ao comportamento e aos vínculos primários" (ALMEIDA, 2019a, p. 208), figurando como importante capital simbólico nas disputas políticas. Na eleição de 2018, a campanha de Jair Bolsonaro deixou claro que as minorias (gays, feministas, "abortistas" etc.) deviam se adaptar à maioria ou, então, deixar o país (ALMEIDA, 2019b). Ainda durante o pleito, circularam memes de fetos abortados, que impingiam às feministas e esquerda o estereótipo de defensores do extermínio em massa de bebês.

12 Termo usado pelos ultraconservadores para sugerir a ideia de "política de morte em massa de fetos". 
Embora a construção da diferença em relação ao adversário seja tolerada na competição política e a "política como guerra" não seja uma novidade no Brasil (ALONSO, 2019), o bolsonarismo eleva a polarização ao máximo, adotando e insuflando recursos ofensivos e segregativos. Suas práticas e discursos tendem a dividir a sociedade em dois polos imisturáveis de bem e mal, com aversão ao contraditório e propagação de ódio à divergência (ABRANCHES, 2019).

No final dos anos 1980, ao trabalhar com ultradireitistas, Pierucci (1987) identificou um forte discurso de crise moral, construído a partir da percepção de que os valores estavam se degenerando, com o afrouxamento do estilo de vida. À época, esse argumento era usado contra migrantes nordestinos, mulheres "liberadas", homossexuais, jovens, usuários de drogas, bandidos etc. A fobia ao aborto também apareceu, muito ligada aos católicos, que eram maioria religiosa no contexto da pesquisa.

Outros trabalhos já analisaram abortos legais envolvendo crianças (vítimas de estupro), como a menina de nove anos, de Lagoinha (PE), que enfrentou uma série de resistências, inclusive de setores religiosos e ultraconservadores, além da ineficiência do próprio Estado na efetivação da política pública, para a obtenção do direito de interrupção da gravidez (BATISTA; SANDERBERG, 2011; LIMA; NJAINE; VERDI, 2014).

No Brasil, existe uma forte articulação antiaborto, mesmo nos casos em que há previsão legal. Os segmentos religiosos conservadores atuam como um dos principais freios na luta das mulheres pelos seus direitos sexuais e reprodutivos. A literatura tem registrado um histórico de ativismo e lobby político muito forte por parte desse setor - inicialmente da Igreja Católica (BATISTA; SANDENBERG, 2011; LIMA; NJAINE; VERDI, 2014; VAGGIONE, 2017; CARRANZA; ROSADO-NUNES, 2020) e mais recentemente também dos evangélicos (ALMEIDA, 2019a; 2019b).

De acordo com Almeida, as estratégias de ação dos neopentecostais, variante religiosa que cresceu vertiginosamente nos últimos anos, variam entre resistir às mudanças (rejeição a qualquer outro tipo de família que não seja a heterossexual), provocar mudanças regressivas (criminalizar o aborto em qualquer situação, retroagindo a legislação dos anos 1940 que tipificou exceções) e aderir a certos valores mais atuais (a ética empreendedora e o aumento da violência do Estado).

Porém, os religiosos não operam sozinhos. Os gestores brasileiros, ao longo da história, têm mostrado falta de coragem e ousadia no enfrentamento da pauta, o que vulnerabiliza o ideal de Estado laico (quando o Estado admite imparcialidade em relação às questões religiosas), bem como enfraquece as 
conquistas já obtidas em relação ao tema (BATISTA; SANDENBERG, 2011). Assim, o Estado também comete um tipo de violência contra essas mulheres, que ocorre exatamente a partir de "vazios no/do sistema", ou seja, dificuldades ou negligências relacionadas ao acesso ao sistema de saúde ou legal, escassez de recursos, precarização do atendimento e/ou restrições ao direito à informação sobre a política pública do aborto (LIMA; NJAINE; VERDI, 2014).

\section{DADOS}

\subsection{Apresentação da comunidade: inegável organicidade}

A comunidade analisada tem se firmado como um importante espaço de interação, mobilização e informação para milhares de pessoas que se autointitulam ou se reconhecem direitistas partidários do presidente da República. Por ali, circula de tudo: comentários sobre política, notícias, informes do governo, correntes de oração, defesa da hidroxicloroquina, convocação para protestos de rua, campanhas de deslike, articulação em torno de hashtags ou enquetes e muita promoção da imagem de Bolsonaro, acompanhada de constantes ataques a figuras percebidas como inimigas: esquerda, Rede Globo, Rodrigo Maia, João Dória, China, STF, Felipe Neto, entre muitos outros.

Uma enxurrada de imagens constrói Bolsonaro ora como herói - a lutar contra a corrupção, contra a esquerda, pela limpeza do país - ora como mito a ofender desafetos, atacar as instituições ou fazer "arminha" com a mão, frequentemente caricaturado com sorriso largo, a pisar em algum inimigo. Também aparece sob as mãos ou o manto de Deus, como seu "protegido" ou "ungido", o Messias salvador.

Links da imprensa que apoia o presidente são postados diariamente, oferecendo aos integrantes a interpretação bolsonarista da realidade, às vezes contada de forma esdrúxula: "Datafolha fica 'de joelhos' para a performance de Bolsonaro"13 ou "Bolsonaro diz: "Na política, sou imbroxável"14. Noutras vezes, farsesca ou delirante: “Olavo de Carvalho desafia Barroso para um

\footnotetext{
${ }_{13}$ Postada em Jornal da Cidade Online. Ver em: <https://www.jornaldacidadeonline.com.br/ noticias/22391/datafolha-fica-de-joelhos-para-a-performance-de-bolsonaro>. Acesso em: 15. out. 2020.

${ }^{14}$ Matéria veiculada no site News Atual. Ver em: <https://www.newsatual.com/bolsonaro-dizna-politica-sou-imbroxavel/>. Acesso em: 15. out. 2020.
} 
debate! E agora Barroso? Vai arregar?"15; e até enganosa: “Jornalista da Globo explica alta de Bolsonaro: 'É o pobre, estúpido'"16 ou "Lula está com coronavírus confirmado pelo hospital Adventista" ${ }^{17}$.

Enquanto a mídia bolsonarista espalha suas visões de mundo - nem sempre factuais ou tolerantes -, a imprensa mainstream sofre boicote. Da CNN a Crusoé, da Globo ao UOL, exceto SBT e Record, os veículos de comunicação são costumeiramente chamados de "esquerdistas", "mentirosos" ou "lixo" e proibidos de circularem no espaço (norma pré-fixada na descrição do grupo).

Também são postados com frequência tuítes, vídeos e/ou comentários de blogueiros, deputados e personalidades pró-Bolsonaro. O signo povo é bastante explorado, como se essa entidade sem corpo incorporasse por completo o chefe do Executivo: "O povo elegeu Bolsonaro" ou "O povo vai às ruas em defesa do presidente" (DIBAI, 2020). Essa estratégia retórica forja a impressão de que o apoio ao líder é maior do que realmente é. Esse fenômeno é chamado pela literatura de "falso consenso" e comum em grupos on-line de partidários altamente engajados com um líder/causa (WOJCIESZAK, 2009, 2011).

Ao observar a conversação, identificamos alguns aspectos que merecem nota. Embora haja perfis falsos, robôs e ações orquestradas, há também organicidade no grupo, com pessoas reais fazendo perguntas, pedindo orações, desejando "bom dia" ou "boa noite", citando suas cidades e estados. Mesmo sendo impossível mensurar a quantidade de pessoas reais, é tolo imaginar que ao lado de Bolsonaro só existem robôs, máquinas, artificialismo e reprodução das mesmas ideias.

$\mathrm{Na}$ interação, existe monitoramento, coordenação e vigilância sobre conteúdos e práticas - os administradores orquestram mudanças no clima de opinião, fazem banimentos, exclusão de mensagens, dão advertências -, mas há também espaço para determinadas divergências. A tolerância com a multiplicidade opinativa varia caso a caso, a depender do tema e do quão "maligno" é julgado o inimigo em questão. Defesas da esquerda, de Lula, do

\footnotetext{
${ }^{15}$ Postada em Jornal da Cidade Online. Ver:

<https://www.jornaldacidadeonline.com.br/noticias/ 22372/olavo-de-carvalho-desafia-barrosopara-um-debate-e-agora-barroso-vai-arregar>. Acesso em: 15. out. 2020.

${ }^{16}$ Essa matéria, publicada no Jornal da Cidade Online, foi considerada falsa pela agência Lupa, em 17/08/20. Ver em: <https://piaui.folha.uol.com.br/lupa/2020/08/17/verificamos-globonewsnordestinos-pobres/>. Acesso em: 15. out. 2020.

17 Print de notícia postado do site Portal24hs.com e desmentido pela agência de checagem Aos Fatos. Ver: <https://www.aosfatos.org/noticias/lula-nao-foi-diagnosticado-com-covid-19-nemfez-teste-no-hospital-adventista/>. Acesso em: 15. out. 2020.
} 
comunismo, da Globo costumam não ser toleradas, tampouco críticas severas a Bolsonaro. Mas diferenças em relação a membros do governo, atuação dos militares e alguns políticos do campo da direita, bem como valores morais ou opiniões sobre a economia tendem a circular sem grande interferência dos administradores, que estão frequentemente presentes na conversação, inclusive se revezam para que o ambiente tenha sempre a presença e o controle de um deles.

\subsection{Entrando no tema: posições antiaborto são predominantes}

Em relação ao caso estudado - da menina de 10 anos que abortou depois de ser estuprada por familiar - notamos que as mulheres se expressaram mais e se mostraram mais incomodadas com o tema. Do total de mensagens, 60,7\% foram postadas por elas. Por vezes, aquelas que opinaram se colocaram na condição de mãe, avó e até "esposa de um ginecologista" ou "grávida de quatro meses". Os homens, em sua maioria, preferiram focar no estupro - no crime, na pedofilia - e não na interrupção da gravidez. A maior parte das postagens expressou algum tipo de sentimento: de um lado, tristeza ou piedade em relação à vítima; do outro, revolta e vontade de vingança contra o agressor.

\subsubsection{Posições contra o aborto}

Como era esperado, as posições contrárias à cessação da gravidez foram bem mais numerosas do que as favoráveis, mesmo nas situações previstas em lei. É como se a maioria do grupo compreendesse o procedimento como inadmissível, uma vez que o rejeitou independentemente da circunstância, agravante, violência e de estar previsto na legislação. É importante destacar que na interface da conversação a força do posicionamento antiaborto foi, além de maior, mais contundente, com o emissor se portando de forma mais ativa e reincidente, inserindo mais conteúdo e buscando mais links de matérias para reforçar sua posição (normalmente mídias bolsonaristas). 


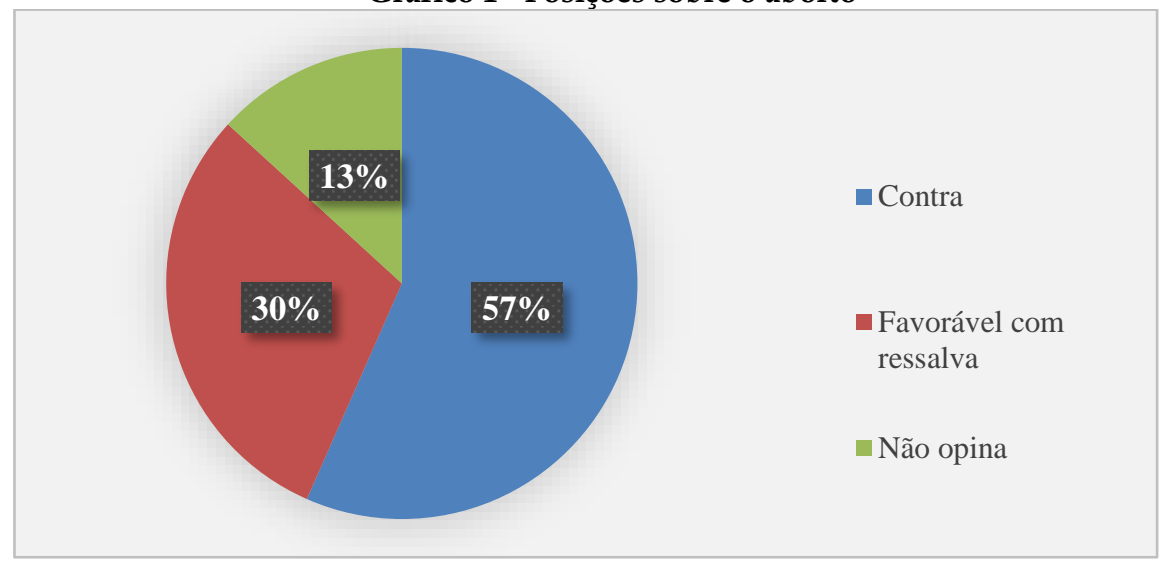

Fonte: Elaborado pelos autores, a partir dos dados.

Os detratores mais radicais da política abortiva compartilharam o vídeo de Sara Giromini, no qual ela divulgava a identidade da criança e o endereço do hospital onde ela seria atendida em Recife (PE). Essa parcela do grupo também publicou mensagem chamando a menina pelo nome, convocando os pernambucanos a se juntarem a uma deputada estadual evangélica e apoiadora do presidente, que organizava protesto em frente à maternidade.

O aborto foi construído como crime "bárbaro", prática "diabólica" ou "assassinato de uma vida indefesa". Os discursos colocavam o nascituro como um ser humano pleno e inocente, que merecia nascer a qualquer custo, independentemente dos riscos para a mãe, do contexto que gerou a gravidez $\mathrm{e}$ da realidade socioeconômica que envolvia a família. O aborto - mesmo sendo previsto como um direito pela legislação brasileira - ganhou status de delito na comunidade, sendo considerado cruel e temerário, inserido na mesma esfera de aversão e ojeriza que o estupro e a pedofilia.

O tuíte do blogueiro Bernardo Kuster ${ }^{18}$, que circulou no grupo, ilustra bem as estratégias dessa direita em mitificar o feto - saudável, inocente, quase seis meses -, dissociá-lo das violências que o circundam, a preencher sua vida de plenitudes imaginadas, e destituir a política do aborto como crueldade e transgressão, tanto do Estado quanto dos profissionais médicos, família ou quaisquer envolvidos.

18 Reproduzimos o tuíte de Kuster por se tratar de uma mensagem pública de uma figura pública, um formador de opinião da direita, que se autointula blogueiro, e postada em sua página do Twitter. 


\section{Imagem 1 - Posições antiaborto}
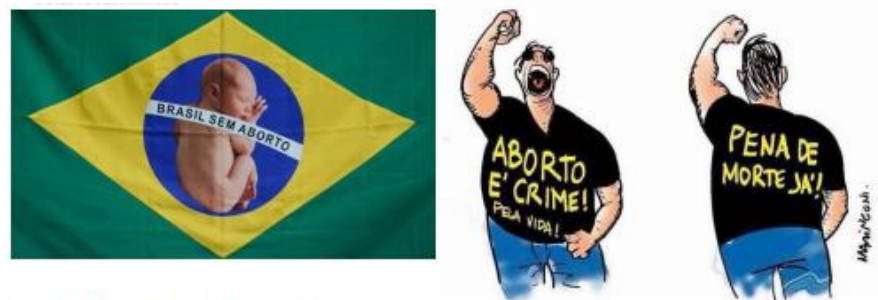

Brasil contra a cultura de morte!

Bernardo P Küster LIVRE ... $\cdot 6$ h

LUTO. | Perdemos a vida da filha

da Menina K. (10 anos) para o

aborto, uma bebê saudável de

quase 6 meses e 500g. Estão

felizes agora? Injetaram cloreto de

potássio no coração dela e

forçarão a extração do cadáver. 0

pedófilo e quem fez 0 aborto têm

de ser punidos. Foi crime! |

Q938 $\backslash 72.190 \bigcirc 6.924$

Fonte: Grupo pesquisado.

A tentativa de criminalizar o aborto legal tem se firmado como uma estratégia duradoura e recorrente dos setores conservadores, que visam apagálo enquanto direito e subverter políticas do Estado a crenças religiosas, o que fragiliza o princípio da laicidade. Como afirma, Lima, Njaine e Verdi, a prática abortiva não deve ser uma questão de delito, mas de direito. "Não de código de crimes, mas de código de direitos." (2014, p. 59).

Os radicais de direita contrários ao procedimento utilizaram ainda os termos "abortista" ou "abortismo" para liberar preconceitos e sentimentos negativos. Polissêmicas, as expressões às vezes foram usadas para destituir a esquerda; noutras, para atacar defensores de criminosos, estupradores e pedófilos; e, muitas vezes, para se referir a ambos: "a esquerdalha amiga de pedófilos". Na visão do grupo, abortista não é apenas a mulher/criança que decide fazer, mas quem realiza (médicos), autoriza (juízes) ou apoia o aborto.

O termo abortismo também serviu ao propósito de polarização social. Assim, o lado do bem, o "nós", ao contrário do lado mau, dos "abortistas", seria "pró-vida", contra a "cultura da morte" ${ }^{19}$, pela defesa do feto indefeso. O grupo entende "cultura da morte" como uma "ideologia perversa que despreza

\footnotetext{
19 Termo aparece, inclusive, na Encíclica Humanae Vitae do papa João Paulo II, que funciona como um documento norteador da Igreja Católica, vinculando a defesa do aborto a uma mentalidade mortífera, considerada desvio de personalidade humana.
} 
crianças e o dom da vida". Essa noção, tal qual ideologia de gênero, funciona como um tipo de "política do mal", em que eles lançam tudo aquilo que repudiam em relação aos direitos sexuais e reprodutivos, desde o uso de contraceptivos até a eutanásia, por exemplo (VAGGIONE, 2017).

Nesse sentido, construíram teorias conspiratórias a respeito da existência de uma indústria pró-aborto, supostamente sustentada por inimigos da direita. A mídia, o feminismo, a esquerda e o globalismo foram apontados como os grandes financiadores desse conglomerado mundial que exterminaria bebês. Donald Trump (ex-presidente dos Estados Unidos e tido como aliado de Bolsonaro) apareceu como uma espécie de "paladino da moralidade", que enfrentava a "maléfica" rede.

A indústria abortista surge como uma fake news de caráter conspiratório, em que os desafetos da extrema direita aparecem unidos e mobilizados para eliminar vidas inocentes. Dessa forma, existe uma ideia de que o inimigo é capilarizado e possui grandes reservas financeiras para investir no propósito da liberação do aborto em nível global, de forma massiva e indiscriminada, por pura crueldade.

\subsubsection{Posições favoráveis ao aborto}

As mensagens favoráveis apresentaram uma particularidade. Todas vieram acompanhadas da ressalva de que o aborto só deveria acontecer na condição exclusiva, pontual e limitada de gravidez por estupro e em crianças, como era o caso da menina capixaba. Não houve nenhuma mensagem nem imagem defendendo a descontinuação gravídica como direito ampliado das mulheres, no que se refere à sua autonomia de decisão e/ou a liberdade sobre o seu corpo.

Esse público utilizou argumentos médicos ou jurídicos como justificativas à sua opinião ("mãe corre risco de morte", "menina é uma criança, não pode ser mãe" ou "pouca idade para parir, pouca idade para criar um filho"), afirmando principalmente que a criança tinha sofrido traumas sérios, enfrentava uma situação médico-psicológica difícil ou era vítima de violência abominável. A idade também apareceu como um moderador importante nesse caso, sendo destacada por diferentes emissores e mensagens. 


\section{Ataques, responsabilizações e soluções propostas}

Os temas do aborto e da pedofilia se imbricaram desde o início da conversação, ocorrendo intensos e paralelos. Enquanto o aborto era ancorado em questões religiosas, a pedofilia culminou em um forte apelo por leis mais rígidas. A reafirmação dos mandamentos divinos se entrecruzou com discursos de ódio à esquerda e à mídia. A vontade de revanche contra bandidos se misturou a rachas no próprio grupo, com a extrema direita acusando a própria militante, Sara Winter, de extremismo.

Gráfico 2 - Distribuição dos temas

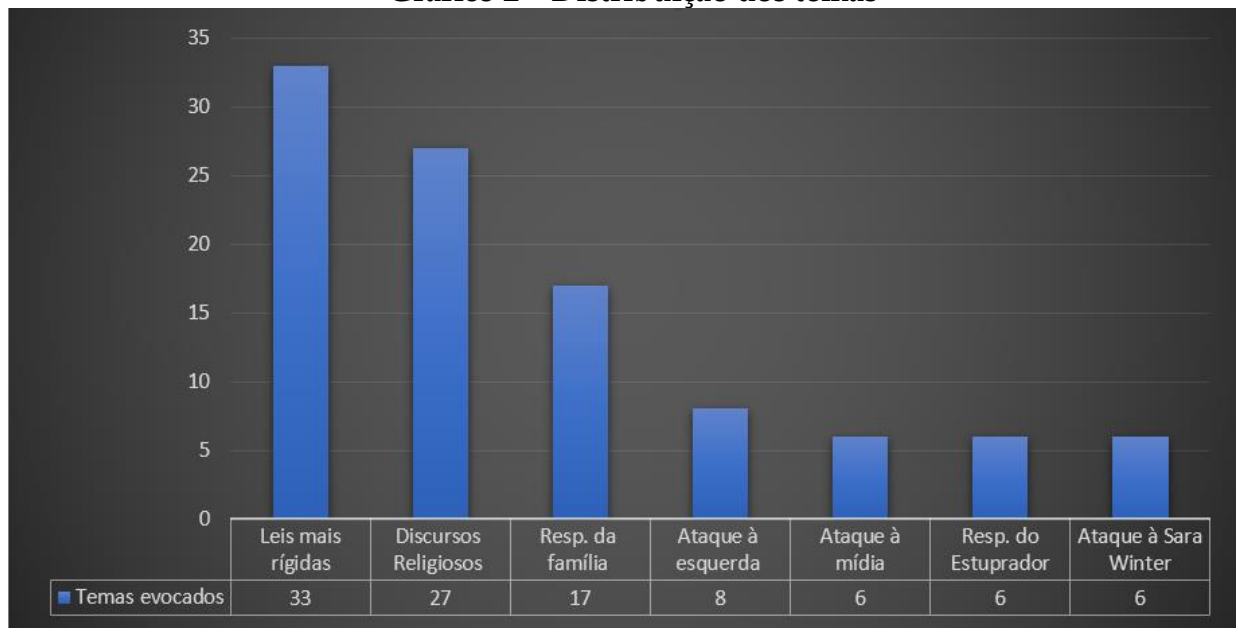

Fonte: Elaborado pelos autores, a partir dos dados.

\subsection{Leis mais rígidas}

A temática mais mencionada em desdobramento ao caso foi a defesa de leis mais rígidas e severas, com pedidos explícitos de mudança no Código Penal Brasileiro, considerado permissivo e "favorável ao bandido". Trata-se de apelos por penas mais duras e longas para indivíduos que praticam pedofilia ou estupro. Entre as modificações mais defendidas, foram citadas a prisão perpétua e a castração química.

A mudança nas leis foi vista como uma solução que só seria alcançada através de governos de direita, sobretudo o do presidente Jair Bolsonaro, pela atribuída postura anticrime. Dessa maneira, apoiar e votar no atual chefe do Executivo apareceu como a última tentativa de implementar penas mais 
severas no Brasil e corrigir o problema do afrouxamento legal-penal que tanto vulnerabiliza o cidadão de bem. $\mathrm{O}$ atual código penal foi percebido como "invertido" ou "uma inversão feita pela esquerda", em que se favorecem os malfeitores sociais em detrimento às vítimas. Os esquerdistas foram construídos como apoiadores de bandidos, libertinos, desordeiros etc.

A noção de justiça construída na comunidade bolsonarista é fortemente associada ao "fazer sofrer" aplicado aos que violam a lei penal (criminosos) ou a moral cristã (mulheres que abortam ou familiares/profissionais que apoiam/realizam abortos). Esse anseio punitivista se ancora tanto na crença de que os delinquentes são naturalmente maus - ou que o crime é sempre uma escolha - quanto na visão de que os criminosos são irrecuperáveis e, por isso, devem "pagar caro" por seus crimes.

Notamos que tais partidários possuem entendimentos controversos sobre direitos à vida e à liberdade, à medida que atribuem plena garantia ao feto que não poderia ser morto, porque já se configuraria como um ser humano constituído -, mas, por outro lado, mostram efetivo incômodo com garantias mínimas a criminosos, bem como com as mulheres que abortam, cuja liberdade e autonomia sobre seus corpos sequer entram nos debates que travam. Assim, a extrema direita representada no artigo tende a entender como portador de direito apenas aqueles que convergem com sua crença, ou seja, o modelo imaginado do "cidadão de bem", enquanto aos outgroups não manifestam preocupações éticas ou legais, tendo dificuldade em reconhecê-los como portadores de garantias ou autonomias.

O discurso por um sistema judicial mais rigoroso, que prenda mais pessoas e por mais tempo, tem se firmado duradouro e recorrente entre os apoiadores da extrema direita no Brasil, desde a redemocratização. Nas eleições de 1985 e 1986, Pierucci (1987) identificou a presença dessa narrativa entre partidários desse segmento ideológico. Mais recentemente, Solano (2018) mapeou o punitivismo como um dos elementos de identificação entre apoiadores e o candidato Jair Bolsonaro. Dibai (2018) apontou ainda a presença de uma forte crítica às leis brasileiras nas falas públicas de Bolsonaro, em seus 30 anos como deputado federal. Entre os temas mais abordados por ele, estiveram: redução da maioridade penal, defesa da castração química para estupradores, pena de morte e prisão perpétua, visão distorcida e limitada dos direitos humanos - no sentido de "mordomia para presos" -, além de trabalho forçado para presidiários (DIBAI, 2018). 


\subsection{Apelos religiosos e visões sobre a família}

Identificamos que grande parte dos comentários que sustentam valorações sobre o aborto se orienta na visão de mundo judaico-cristã, sendo a narrativa bíblica e a noção de família exclusivamente heterossexual e temente a Deus instrumentos de ancoragem à modulação das posições contrárias ao aborto. Pelos dados, notamos forte presença de posicionamentos de matrizes evangélica e católica, ao mesmo tempo que não encontramos mensagens autodeclaradas nem símbolos manifestados das religiões espírita, candomblecista e umbandista. Ficou claro que os católicos e os evangélicos apresentaram, na conversação analisada, tendência a opiniões convergentes.

Pela descrença na "lei dos homens" - branda e injusta -, nas instituições contaminadas pela corrupção - e no próprio Estado democrático de direito promotor da desordem -, os membros apelam à religião cristã como a única força capaz de dar um "reset" na sociedade e estancar males, sofrimentos e abortos. Os usuários de perfil religioso tenderam ainda a demarcar sua posição com base na polarização "forças de Deus" versus "forças malignas" (diabo, demônio, Lúcifer), simplificada na díade "cristãos" versus "abortistas".

As faces do Deus cristão são modalizadas de forma seletiva. Se, por um lado, é extremamente misericordioso e capaz de preservar intactas a vida da menina e a do bebê; por outro, é irado e punitivo com "abortistas", estupradores e pessoas/instituições julgadas "omissas" à "Lei de Deus" (inclusive o Judiciário e/ou a medicina, quando se colocam ativos em circunstâncias relacionadas ao aborto).

Em uma imagem em circulação no grupo, o feto chegou a ser comparado a Jesus Cristo, sendo ambos marcados pelos estereótipos de "inocente, sem culpa e condenado à morte". As ideias de "pureza absoluta" e "morte injusta" se misturaram para construir apelos sentimentais negativos, como se a prática abortiva fosse, ao mesmo tempo, barbárie e injustiça.

Em outra montagem, o aborto, o ateísmo, as drogas, a homossexualidade, a pornografia e o feminismo aparecem como ideias deturpadas que destruirão a família e, por consequência, a civilização ocidental. Seguindo essa interpretação, cujo tom de alarmismo e ameaça é marcante, a família seria a unidade civilizatória mínima, cujo desmantelamento implicaria o fim da própria sociedade. Essa visão conspiratória, excludente, divinizada e machista de organização familiar reforça o status quo e sua estrutura de preconceitos e desigualdades, buscando conter avanços societários em relação às identidades não hegemônicas. 

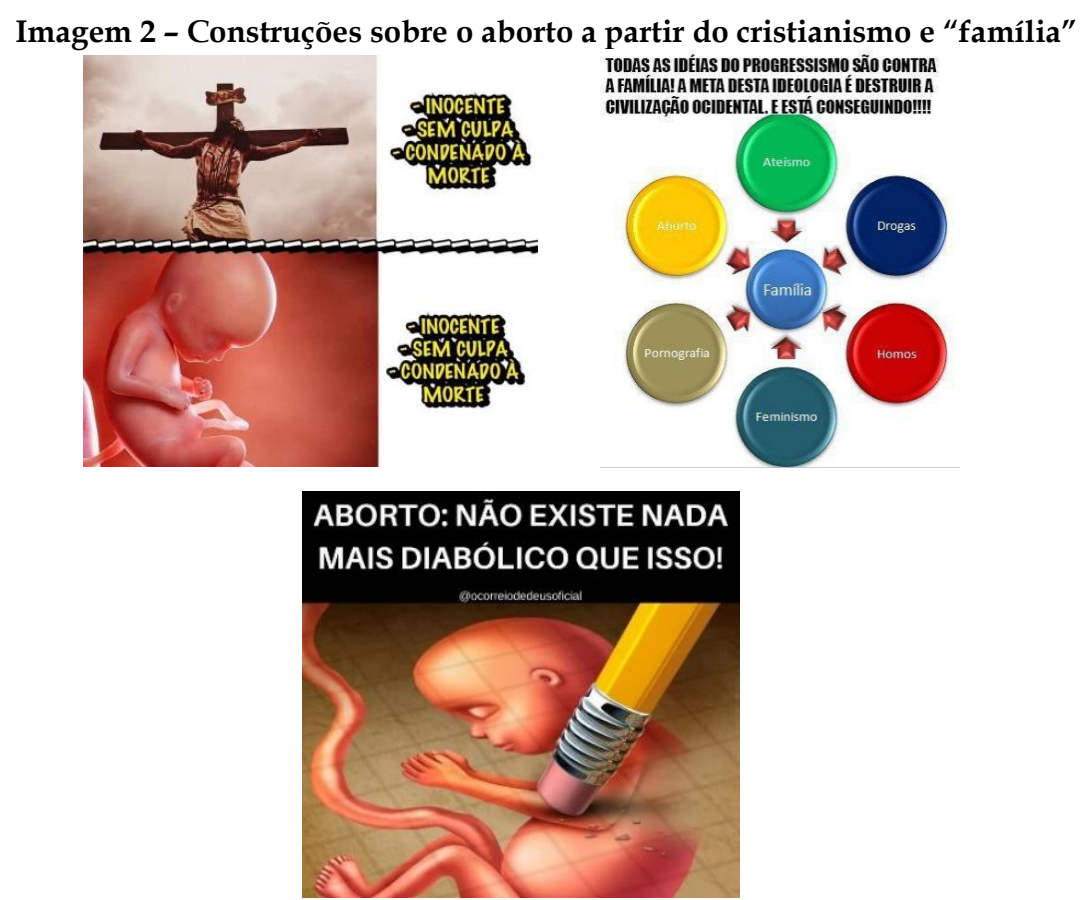

Fonte: Dados da pesquisa.

Assim, notamos, no grupo, a presença de uma luta simbólica que tenta passionalizar a causa e mobilizar os adeptos contra o aborto, a ideologia de gênero e o progressismo, a partir de ameaças, conspirações, estereótipos negativos e polarização severa. Nesse sentido, o simbolismo dos mandamentos e textos bíblicos é explorado ao máximo, reforçando os dogmas do cristianismo como a base central e universal da sociedade, a verdade secular, estabelecida e incriticável.

$\mathrm{Na}$ comunidade, circula fortemente a ideia de que a ordem da realidade deve estar submetida à "vontade de Deus" ${ }^{20}$, ou seja, a normas cristãs, impostas como único caminho para salvar o mundo do mal, do caos, do demônio, dos ímpios. Dessa forma, a batalha em relação ao aborto e questões relacionadas à sexualidade e reprodução se dá, em grande medida, por artifícios simbólicos e não argumentos objetivos, legais ou de base científica. Essa tentativa dos movimentos religiosos cristãos de impor seus valores e crenças como universais, ao passo que mina as lutas pela autonomia das

\footnotetext{
${ }^{20}$ Vale destacar que os comentários de cunho religioso extraídos do grupo são opiniões breves, sem grande embasamento teológico, teórico ou mesmo citações retiradas da Bíblia.
} 
mulheres ou gays, fragiliza o ideal de laicidade do Estado e compromete a efetivação tanto da lei quanto das políticas públicas já existentes nessas áreas (BATISTA; SANDENBERG, 2011).

No caso dos apoiadores de Bolsonaro, há ainda, para além da luta política, práticas de segregação que sugerem a presença de um fundamentalismo autoritário, cuja governança dos corpos e das vidas é tecida a partir do ódio aos diferentes e às minorias, no que PY (2020) chama de "cristofascismo". Visitas para intimidar a família da menina (quando ainda estava no Espírito Santo), utilização da máquina estatal para evitar o procedimento, divulgação dos seus dados em rede social à revelia da lei e/ou protestos em frente à maternidade, chamando os médicos de "assassinos", são expressões dessa visão religiosa radical, cuja vigilância se impõe à compaixão, o expurgo ao ímpio se sobressai à tolerância e o "atirar pedras nos pecadores" legitima a violência como enredo divino.

De forma geral, os radicais de direita analisados mostraram incômodo com o que reconhecem como "famílias desestruturadas" e incluem a da menina capixaba nesse estereótipo. Por vezes, manifestaram: "cadê a mãe dessa menina?", "cadê os responsáveis?", "ninguém viu nada?", "qual a estrutura dessa família?", "a criança não tinha ninguém, só os avós?" etc.

No grupo, circulou a ideia de que quanto mais cristã e tradicional a família (com presença de pai e mãe casados, temente a Deus e seus princípios), menor a chance de haver prática de aborto, de modo que grupamentos familiares destoantes desse modelo seriam mais suscetíveis a abortar. Também o cuidado dos pais é percebido como um mecanismo decisivo de prevenção às violências contra a criança, de modo que genitores vigilantes e rigorosos na criação dos filhos seriam capazes de evitar o estupro e a pedofilia.

Porém, pesquisas e informações oficiais não dão sustentação a essa crença. Segundo dados do Ministério da Saúde, de 2017, a maioria das mulheres que interrompe a gravidez está em uma união estável e é católica. Além disso, quanto maior a renda e a escolaridade, maiores as chances de a primeira gravidez ser interrompida (SOARES; NOVAIS, 2019). Também as pesquisas de Diniz e Medeiros (2010) e Diniz, Medeiros e Madeiro (2017) enfraquecem esse tipo de visão, mostrando que mulheres de todas as religiões realizam abortos, em especial as de tradição cristã (católicas e evangélicas/protestantes). Além disso, apontam que o aborto no Brasil ocorre de forma abrangente, em todas as regiões do país, em todos os níveis educacionais, estados civis, classes sociais, grupos raciais e em mulheres empregadas e desempregadas (DINIZ, MEDEIROS; MADEIRO, 2017). 
Os usuários também apontaram instituições midiáticas como corresponsáveis pela desorganização da família heterossexual-cristã. Emissoras como Globo, CNN e Band foram responsabilizadas como produtoras de conteúdos de cunho antifamiliar, que engloba desde a erotização das crianças até a massificação de estilos de vida ultrajantes. A solução encontrada no grupo é radicalizada: "destruir" a mídia tradicional.

\subsection{Contra Sara Winter}

A repercussão em torno das atitudes de Sara Giromini, em relação ao caso da menina de 10 anos, foi um dos assuntos que rendeu engajamento. Na noite do dia 18/08, ela passou a ser o foco da conversação, após um dos membros especular que, pela postura radical adotada, ela seria presa novamente. Antes disso, no dia 17/08, já havia sido mencionada e criticada em função de ter divulgado publicamente os dados da criança, expondo uma "inocente".

As ocorrências mostraram discordância em relação ao comportamento da militante e antipatia/desaprovação a sua pessoa. Ficou clara a tentativa de os partidários de se dissociarem dela - "não somos como ela", "ela não tem nada de uma pessoa de direita" -, associando Giromini à imaturidade, ao descrédito e ao radicalismo, afirmando que ela tinha "alma de esquerdista" (em alusão a seu passado como suposta feminista), que só fazia besteira e desmoralizava o campo da direita.

Os usuários colocaram em dúvida, inclusive, se ela seria, de fato, direitista, alegando que a ativista agia por interesses pessoais, "gostava muito de aparecer" (chamar a atenção), era exagerada, imprudente e colocava em risco o apoio das pessoas ao presidente Bolsonaro, ao agir de forma intempestiva e turbulenta. Um integrante culpou Sara por radicalizar o debate e transformar o tema do aborto em "briga", permitindo que a esquerda os acusasse de extremistas e radicais.

Giromini foi construída negativamente, chamada de "suicida" ou de quem só "toma decisões erradas", à medida que viveria a se autoprejudicar e sabotar. Nesse sentido, foi considerada alguém que "se entrega de bandeja à esquerda", "dá munição ao STF" ou "não pensa no filho antes de agir". A ação de divulgar os dados da criança foi construída como uma "maldade que foi longe demais", uma "ação de marketing pessoal", um gesto que causou um enorme desgaste para o presidente. Adjetivos como "desumana", "maldosa", "agitadora" e "hipócrita" também foram associadas à ativista. 
A negativação de Sara Winter, nesse caso, se mostrou um registro interessante, porque até o indiciamento pelo STF, em junho de 2020, quando foi presa, ela gozava de boa fama no grupo, sempre vinculada a Damares Alves e/ou à luta em favor do presidente - como a líder da milícia “300 do Brasil”. É importante pontuar, porém, que não houve imagens/montagens de desqualificação da militante, de modo que sua desconstrução ocorreu exclusivamente via mensagens de texto.

\section{Pedofilia e desinformação intencional}

O caso analisado resgata um discurso caro à extrema direita: a pedofilia. A temática foi explorada nos textos e nas imagens, tida como um mal, um crime imperdoável, um ato repulsivo. Sendo assim, a violência (agressão ou tiro) foi admitida como vingança/punição aos pedófilos. A ideia de justiça com as próprias mãos apareceu como possibilidade anunciada. Usando conjugação em primeira pessoa, muitos relataram o que fariam com o pedófilo ou estuprador caso a filha ou família fosse a vítima: "cortaria", "arrancaria", "mutilaria", "deixaria vivo para sofrer".

Imagem 3 - Imagens que sugerem violência no enfrentamento da pedofilia
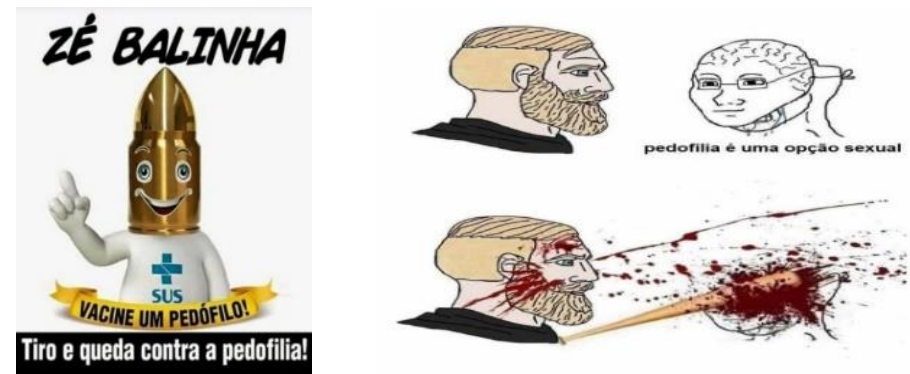

Fonte: grupo on-line pesquisado

A esquerda foi associada à pedofilia, de modo que partidos e militantes desse espectro foram construídos como defensores da violência. Outras personalidades também foram falsamente colocadas na condição de apoiadores. Isso aconteceu com Felipe Neto (youtuber), Celso de Mello (ministro do Supremo Tribunal Federal), Drauzio Varella21 (médico e

${ }^{21}$ Dráuzio Varella é citado na temática da pedofilia, em razão de matéria feita ao programa Fantástico sobre transexuais presos (03/20). Na ocasião, ele entrevistou e abraçou uma presa, que depois se soube ter sido condenada por estupro e assassinato de uma criança. Dráuzio afirmou não 
apresentador de TV) e até Joe Biden (opositor de Donald Trump na eleição dos Estados Unidos).

O youtuber Felipe Neto, em especial, com maior número de posts contrários, foi chamado de pedófilo, hipócrita e "péssima influência para as crianças". Neto tem figurado como inimigo do bolsonarismo desde que passou a criticar Jair Bolsonaro em suas redes sociais e na imprensa, inclusive em entrevista ao The New York Times, em 22/07/20.

\section{Imagem 4 - Imagens que associam adversários à pedofilia}

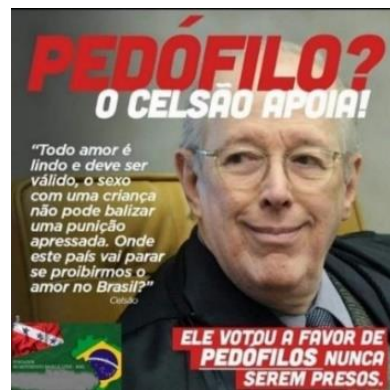

\section{O MUNDO TÁ PERDIDO 8 \\ UM PEDÓFILO OFERECENDO}

Frof CENT
Felipe Neto se oferece para
pagar educação de menina de 10

anos grávida por estupro

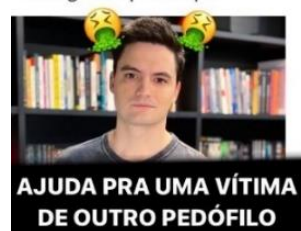

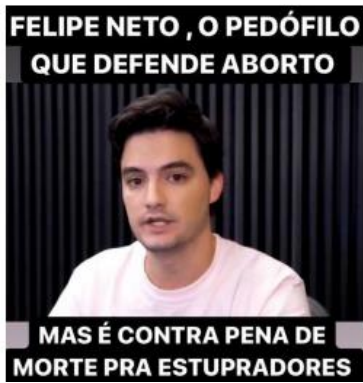

(앙

Patriotas

@PATRIOTAS

Vamos lembrar que no início do

ano Drauzio Varella no

fantástico romantizou um

estuprador e assassino de

criança. E muitos daqueles que

hoje se dizem "preocupados"

com a criança de 10 anos

abusada, defenderam Drauzio e

o assassino.

Fonte: Grupo on-line pesquisado.

Além de acusações incomprovadas a inimigos, também circulou no grupo a informação falsa de que a França teria liberado o aborto até o nono mês de gestação $^{22}$ e a de que as feministas haviam sequestrado a criança para levá-la a abortar. Outra desinformação proveio de tuíte de Sara Giromini de que o

saber dessa informação no momento da entrevista. Os bolsonaristas exploraram o caso, atacando Dráuzio por "humanizar pedófilo".

22 Informação considerada falsa pelas agências de checagem: Lupa e Estadão Verifica. Ver mais em: $<$ https:// politica.estadao.com.br/blogs/estadao-verifica/assembleia-nacional-francesa-naoliberou-aborto-voluntario-ate-o-nono-mes-de-gestacao/>. Acesso em: 10. out. 2020. e $<$ https://piaui.folha.uol.com.br/lupa/2020/08/ 12/verificamos-assembleia-nacional-da-francaaborto-9-meses/>. Acesso em: 10. out. 2020. 
aborto em decorrência de estupro só poderia ser realizado até a $20^{a}$ semana de gravidez. No entanto, pela legislação brasileira, não há limite de tempo ou idade da mulher para a realização do procedimento.

\section{Conclusão}

Nos últimos anos, com a (re)ascensão de uma direita mais radical no Brasil, pautas pela defesa intransigente da família heterossexual-cristã, do aborto e controle dos corpos femininos, além de penas mais severas para pedófilos e estupradores, ganharam relevância e centralidade no debate público. A vitória presidencial de Jair Bolsonaro e do movimento conhecido como bolsonarismo tem atuado para transformar essas bandeiras em políticas de Estado.

Os dados analisados revelaram que parte expressiva dos apoiadores do presidente se declarou contrária ao aborto legal, independentemente do motivo ou circunstância. Ainda que alguns usuários tenham se colocado favoráveis à interrupção da gravidez, fizeram questão de pontuar a excepcionalidade da ocorrência como motivador da opinião.

A pesquisa também identificou um movimento de desaprovação e uma tentativa de descarte político da ex-aliada Sara Giromini, que foi considerada prejudicial ao bolsonarismo, percebida como "muito radical", "muito imatura" ou "alma de esquerdista". Em resposta à pedofilia, a comunidade virtual clamou por penas mais duras (castração química e sentenças mais longas), com forte discurso revanchista contra bandidos.

A visão dos participantes seria de que existe uma falência da família, do Estatuto da Criança do Adolescente (ECA) e do Conselho Tutelar, fatores que favoreceriam à criminalidade e impunidade contra crianças e adolescentes. Desta forma, foi construído um "punitivismo jurídico" (AVRITZER, 2020), uma ideia de que seria necessário substituir as leis vigentes por uma concepção moral-conservadora judicialmente sancionada, que passaria pelo empoderamento da família tradicional e do reconhecimento dos pais como a principal e legítima autoridade sobre os filhos.

O sentido de "justiça realmente justa" foi construído sob o prisma da aplicação de dor e sofrimento àqueles que cometem o crime de pedofilia e estupro. Existe dentro da comunidade virtual uma visão dicotômica e moralizante de que o criminoso representa não só o mal, mas o mal protegido pelo Estado (SOLANO, 2019b). Ademais, mostra a força de um movimento sinalizado por Garnier (2016) de substituição do Estado social pelo Estado penal, com menos benefícios sociais, menos seguridade para o trabalhador, 
menos políticas de reparação sócio-históricas, e, por outro lado, leis mais rígidas, prisões mais seguras, penas mais duras, formas de ordem e controle social mais abrangentes e autoritárias, com absoluta autonomia às forças de segurança.

No geral, a ofensiva antiaborto produziu uma série de rechaços: 1) sobre a criança, que teve os dados divulgados; 2) seus familiares, principalmente os avós, atacados por deixarem ou autorizarem a criança a abortar; e 3) médicos e juízes, que, como parte do Estado, legitimaram e viabilizaram o processo de interrupção da gravidez. Esquerda, movimentos feministas e a mídia também foram modalizados como inimigos a serem combatidos.

O apelo à manutenção do projeto de extrema direita dentro do grupo é visto como a única e última tentativa de aniquilação dos adversários impuros e de construção de uma nova sociedade. De modo geral, existe um anseio de que o inimigo seja punido pela "vontade de Deus" e/ou aniquilado pela máquina do Estado penal direitista.

Tanto a repulsa pelo aborto quanto a exigência de leis mais severas passaram pela invocação da religião. É notório um pensamento fortemente cristão em defesa de uma sociabilidade impositiva. A pedofilia também é um subtema convocado e canaliza discursos de ressentimento, ira e descrença na sociedade, com menções até a justiça com as próprias mãos.

Casos de violência sexual que culminam em gravidez envolvendo crianças não são raros no Brasil. Em 2009, uma menina de nove anos, de Lagoinha (PE), vítima de estupro por parte de familiar, também ganhou o direito a abortar e, tal qual o episódio que analisamos, enfrentou dificuldades para a efetivação desse direito. Tanto profissionais de saúde quanto a Arquidiocese de Pernambuco, entre outros, se posicionaram contrários ao aborto legal, ainda que, naquela ocasião, autoridades federais (presidente da República e ministro da Saúde) tenham marcado posição pública em separar as questões religiosas das ações/políticas do Estado (BATISTA; SANDERBERG, 2011), diferentemente do contexto revelado no nosso caso.

Existe um histórico de luta pelos direitos sexuais e reprodutivos das mulheres, com uma série de avanços e retrocessos, que, no entanto, não trataremos neste artigo. É importante pontuar, no entanto, que, para os movimentos feministas, o aborto não é apenas uma questão de saúde pública, mas integra um conjunto variado de lutas pela ampliação dos direitos das mulheres - incluindo autonomia de decisão e liberdade sobre o corpo.

Apesar das dificuldades da pesquisa de tentar extrair valores e crenças de uma conversação on-line fragmentada e multitemática - sem informações 
sociodemográficas dos opinantes e sem qualquer controle do ambiente pesquisado -, acreditamos que este trabalho oferece contribuições interessantes sobre a visão de mundo da extrema direita brasileira, na atualidade. Além disso, utiliza como fonte de dados a plataforma Telegram, ainda pouco explorada.

\section{Referências}

ABRANCHES, Sérgio.

(2019). Polarização radicalizada e ruptura eleitoral. In: Vários Autores (orgs). Democracia em risco: 22 ensaios sobre o Brasil hoje (Edição Kindle). São Paulo: Companhia das Letras, p. 6 $-21$.

ALMEIDA, Ronaldo.

(2019a). Bolsonaro presidente: Conservadorismo, evangelismo e a crise brasileira. Novos estudos Cebrap. São Paulo, v. 38 , n. 1, p. 185-213.

ALMEIDA, Ronaldo.

(2019b). Deus acima de todos. In Vários Autores. Democracia em risco: 22 ensaios sobre o Brasil hoje (Edição Kindle). São Paulo: Companhia das Letras, p. 22-33.

ALONSO, Angela.

(2019). A comunidade moral bolsonarista. In: Vários Autores (orgs), Democracia em risco: 22 ensaios sobre o Brasil hoje (Edição Kindle). São Paulo, Companhia das Letras, p. 35-45.

AVRITZER, Leonardo.

(2020). Política e antipolítica. A crise do governo Bolsonaro (Edição Kindle). São Paulo: Todavia.

BATISTA, Carla Gisele; SARDENBERG, Cecília M. B. (2011). Movimentos feministas, aborto e laicidae o caso de Alagoinha como exemplar. In: BONNETI, Alinne; LIMA E SOUZA, Ângela Maria Freire de (org.), Gênero, mulheres $e$ feminismos. Salvador: EDUFBA: NEIM. p.243260.

BAUER, Martin.

(2015). Análise de conteúdo clássica: uma revisão. In: BAUER, Martin; GASKELL, George (org.), Pesquisa qualitativa com texto, imagem e som: um manual prático. Petrópolis:Editora Vozes, p. 189-217.

BIROLI, Flávia; CAMINOTII, Mariana.

(2020). The Conservative Backlash against Gender in Latin America. Politics \& Gender, v.16, n. 1, p. 1-38.

CARRANZA, Brenda Maribel; ROSAD0-NUNES, Maria José Fontelas.

(2020). Fim de uma ordem: natureza, lei divina, feminismo. Horizonte: Revista de Estudos de Teologia e Ciências da Religião (Online), v. 1, p. 936-964.

CHADE, Jamil.

(2020). Brasil e EUA articulam aliança mundial antiaborto. Disponivel em: https://noticias.uol.com.br/colunas/jamilchade/2020/09/02/brasil-e-eua-queremliderar-alianca-mundial-antiaborto.htm. Acesso em: 15 set. 2020.

DIBAI, Priscilla.

(2018). A direita radical no Brasil pósredemocratização: o caso de Jair Bolsonaro. Dissertação apresentada ao Programa de PósGraduação em Ciências Sociais da Universidade Federal da Bahia.

DIBAI, Priscilla.

(2020). Bolsonarismo on-line: "Com ou sem democracia, salvemos o capitão!". Revista Tensões Mundiais, v. 16, n. 30, p. 177-211.

DINIZ, Debora; MEDEIROS, Marcelo.

(2010). Aborto no Brasil: uma pesquisa domiciliar com técnica de urna. Ciência \& Saúde Coletiva, v. 15, p. $959-966$. 
DINIZ, Debora; MEDEIROS, Marcelo; MADEIRO, Alberto.

(2017). Pesquisa nacional de aborto 2016. Ciência \& Saúde Coletiva, v. 22, p. 653660.

GARNIER, Jean-Pierre.

(2016) "A sociedade do risco": um medo que tranquiliza? In COLOMBO, Eduardo; CREAGH, Ronald; CASTELLANOS, Heloisa; GARNIER, Jean-Pierre (Org.). Políticas do medo. São Paulo, Editora Intermezzo, p. 11-38.

KALIL, Isabela; KALIL, Álex; PALUDETTI, Felipe; MELO, Gabriela; PINHEIRO, Weslei; AZARIAS, Wiverson.

(2018). Quem são e no que acreditam os eleitores de Jair Bolsonaro. Disponivel em: https://www.fespsp.org.br/upload/usersfiles/ 2018/Relat\%C3\%B3rio\%20para\%20Site\%20F ESPSP.pdf. Acesso em: 15 out. 2020.

LIMA, Rita de Cássia Gabrielli Souza; NJAINE, Kathie; VERDI, Marta.

(2014). 0 aborto no Brasil em debate: Polêmicas e contradições envolvendo violência sexual na infância. Saúde \& Transformação Social/Health \& Social Change, v.5, n.3, p.54.-62.

MARANHÃO, Eduardo M. de A.; COELH0, Fernanda M. F.; DIAS, Tainah B.

(2018). Fake news acima de tudo, fake news acima de todos": Bolsonaro e o "kit gay", "ideologia de gênero" e fim da "família tradicional. Revista Eletrônica Correlatio, v. 17, n. 2, p. 65-90.

MESSENBERG, Débora.

(2019). A cosmovisão da "nova direita brasileira". In: PINHEIRO-MACHADO, Rosana; FREIXO DE ALMEIDA (Org.); Brasil em Transe: Bolsonarismo, Nova Direita e Desdemocratização (Edição Kindle). Rio de Janeiro: Oficina Raquel, p. 311-673.

PIERUCCI, Antônio Flávio.

(1987). As bases da nova direita. Revista Novos Estudos Cebrap, v. 19, p. 26-45.
PY, Fábio.

(2020). Cristofascismo, uma teologia do poder autoritário: a união entre o bolsonarismo e o maquinário político sócio-religioso. [Entrevista concedida a Patricia Fachin e João Vitor Santos]. Disponível em: http://www.ihu.unisinos.br/600150cristofascismo-a-uniao-entre-o-bolsonarismoe-o-maquinario-politico-socio-religiosoentrevista-especial-com-fabio-py. Acesso em: 27 jul. 2020.

SOARES, Gabriela; NOVAIS, Maria Clara.

(2020). Quem são elas: o perfil das mulheres que abortam no Brasil. Disponivel em: https://diplomatique.org.br/quem-sao-elaso-perfil-das-mulheres-que-abortam-nobrasil/. Acesso em: 20 set. 2020.

SOLANO, Esther.

(2018). Crise da democracia e extremismo de direita. Friedrich-Ebert-Stiftung, n. 42, p. 327.

SOLANO, Esther.

(2019a). La Bolsonarización de Brasil. Documentos de Trabajo (IELAT, Instituto Universitario de Investigación en Estudios Latinoamericanos). n. 121, p.1-42.

SOLANO, Esther.

(2019b). Quem é o inimigo? Retóricas de inimizado nas redes sociais no período de 2014-2017. In: MACHAD0, Rosana Pinheiro; FEIX0, Adriano de. Brasil em transe: Bolsonarismo, Nova Direita e Desdemocratização (Edição Kindle). Rio de Janeiro, Oficina Raquel, p.83-98.

VAGGIONE, Juan Marco.

(2017). La Iglesia Católica frente a la política sexual: la configuración de uma ciudadanía religiosa. Cad. Pagu, p.1-35. 
VILA-NOVA, Carolina.

(2020). Ministra Damares Alves agiu para impedir aborto em criança de 10 anos. Disponível em: https://www1.folha.uol.com.br/cotidiano/20 20/09/ministra-damares-alves-agiu-paraimpedir-aborto-de-crianca-de-10-anos.shtml. Acesso em: 27 ago. 2020.

WOJCIESZAK, Magdalena.

(2009). What underlies the false consensus effect? How personal opinion and disagreement affect perception of public opinion. International Journal of Public Opinion Research, v. 21, n. 1, p. 25-46.
WOJCIESZAK, Magdalena.

(2011). Computer-Mediated False Consensus: Radical Online Groups, Social Networks and News Media. Mass Communication and Society, v. 14, n. 4, p. $527-546$.

\section{Recebido em}

outubro de 2020

\section{Aprovado em}

novembro de 2021 